\title{
Acceptability of Vaccination Against COVID-19 Among Se- lected Residents of the Cities of Caloocan, Malabon, and Navotas, Philippines
}

\author{
Angelito P. Bautista Jr. ${ }^{1}$ *, Doris G. Bleza ${ }^{2}$, Dianne M. Balibrea ${ }^{1}$, and Cynthia Equiza ${ }^{2}$ \\ 1 Blue Chips Research and Consultancy Co.; dbalibrea.bluechips@gmail.com \\ 2 Polytechnic University of the Philippines; dgbleza.bluechips@gmail.com; mccee1830@yahoo.com \\ * Correspondence: apbautistajr2020@gmail.com
}

\begin{abstract}
With COVID-19 vaccines slowly being rolled out in many countries, it is important to understand the public's acceptance of being vaccinated. This study aims to study the willingness and motivations among residents of the cities of Caloocan, Malabon, and Navotas, Philippines to be vaccinated against COVID-19. Based on an online survey of 137 respondents, who willingly participated in the study, $71 \%$ will take a COVID-19 vaccine if it becomes available, with similar rates among respondents from Caloocan (82\%), Malabon (83 \%), and Navotas (81\%). If a vaccine is proven safe and effective, more respondents (82\%) will take a COVID-19 vaccine. Furthermore, safety against COVID-19 as well as the safety and effectiveness of vaccines are the primary factors why respondents are willing or unwilling to get a vaccine. The results highlight the need for effective messaging that promotes COVID-19 vaccination, with emphasis on the safety and effectiveness of the vaccine, and its benefits to the public, especially that the vaccines that will be delivered in the country in the next few months are not the most preferred brands by the respondents.
\end{abstract}

Keywords: COVID-19; vaccine acceptance; vaccine willingness; vaccine hesitancy; quantitative; online survey; Philippines

\section{Introduction}

The coronavirus disease (COVID-19) was first identified in Wuhan, China at the end of December 2019, and was declared a pandemic by the World Health Organization (WHO) on March 12, 2020 [1]. The virus has affected almost all countries, resulting in more than 140 million cases recorded, and at least 3.0 million global deaths. In the Philippines, more than 900,000 cases and 15,000 deaths have been confirmed [2].

Because the virus was new, antivirals and therapeutic solutions have not been developed; minimum health standard measures were put in place to slow the spread of the virus. The public was asked to wear face masks and practice physical distancing. In many instances, especially when infections rise quickly, strict quarantine measures were implemented. While these countermeasures are remarkable, they are still not sufficient to completely halt the spread of COVID-19 [3]. Vaccination is considered an important additional tool and the most successful way to control the viral infection and spread of COVID-19 $[4,5]$. The rapidly growing global infection rate of the virus has forced international governments and organizations to urgently produce vaccines as soon as possible [5]. Several vaccines have been approved for general, limited, or emergency use in countries like China, Russia, the United Kingdom (UK), and the United States (US) [6]. In December 2020, the WHO issued its first emergency validation for the Comirnaty COVID-19 mRNA vaccine developed by Pfizer/BioNTech [7]. UK was the first to roll out a mass vaccination program, followed by the US [8,9]. As of February 2021, more than 100 million doses have been administered globally, with countries like Israel and the 
United Arab Emirates making swift progress to immunize their citizens, while others are vaccinating small proportions of their populations [6].

Data from the WHO has revealed that there are 181 vaccines in pre-clinical developments, while another 69 are in clinical development as of February 2021 [10]. Some of the vaccines currently in the clinical stage are being developed by AstraZeneca and the University of Oxford, Cansino Biological Research, Gamaleya, Moderna, Pfizer, Sinovac, and Sinopharm to name a few.

The Philippine government originally aimed to start its vaccination program as soon as February 2021 [11]. The government was aiming to secure at least 148 million vaccine doses and vaccinate 50 million to 70 million Filipinos within the year to reach herd immunity against COVID-19 [12]. The Philippine Department of Health (DoH) has also expressed optimism that the country will receive around 44 million doses through the COVID-19 Vaccines Global Access (COVAX) facility, which "provides governments with the opportunity to benefit from a large portfolio of COVID-19 candidate vaccines using a range of technology platforms, produced by more manufacturers across the world, with a bigger market to provide security of demand [13,7]." Two brands of COVID-19 vaccines are expected to be delivered by end of February and early March 2020 - Sinovac and AstraZeneca [14].

Even though immunization has successfully reduced the global burden of illness and death, public confidence in vaccines can be affected by various concerns [3]. Concern about vaccines has been growing worldwide, with several factors being found responsible for vaccine acceptancy when a new vaccine is developed [15-19]. Even the WHO has identified vaccine hesitancy as one of the top ten threats to global health [20].

The problem of vaccine refusal has many contributing factors $[4,21,22]$. Some of the factors resulting in vaccine hesitancy include the safety and efficacy of the vaccine, side effects of the vaccine, misconceptions about vaccination, and lack of knowledge [23,24]. Vaccine hesitancy and misinformation have caused substantial obstacles to achieving coverage and herd immunity, which could put public health at risk, especially if it persists during the present crisis $[15,16,18]$. In fact, in many cases, people's hesitation to be vaccinated or have their children vaccinated has resulted in localized outbreaks of vaccine-preventable diseases [25]. The most well-known example in the Philippines is the outbreak of measles in 2018-2019 and resurgence of polio in 2019 [26; 20], which were attributed to the fundamental breakdown in public trust in vaccines after local health authorities withdrew a dengue vaccine (Dengvaxia $\left.{ }^{\circledR}\right)$ in 2017 [27]. A report by the United Nations Children's Fund (UNICEF) in 2019 showed that the measles immunization coverage in the Philippines has declined from 88\% in 2013 to 73 \% in 2017, and moved further down to less than 70\% in 2018 [28]. DoH Secretary Francis Duque admitted that vaccine hesitancy contributed to the worsening problem of low vaccine coverage [27].

When it comes to the COVID-19 vaccine, a national survey conducted by Pulse Asia from November 3 to December 2, 2020, revealed that almost half (47\%) of Filipinos said they are not willing to get vaccinated against COVID-19. Meanwhile, an independent survey in NCR by the OCTA Research, an independent interdisciplinary group composed of scientists from the University of the Philippines (UP), the University of Santo Tomas (UST), and Providence College in the United States, showed that only $25 \%$ percent of 600 respondents aged 18 above are willing to be vaccinated against COVID-19 [29].

The WHO has recommended a preemptive strategy to overcome vaccine hesitancy and build trust in a vaccine to prepare for maximum efficacy when a vaccine is available [4]. The efficient and effective distribution and acceptance of COVID-19 vaccines among the general public is a crucial challenge to ensure that herd immunity can be achieved. The negative issues toward vaccines in the past have negatively affected the public's intention to be vaccinated against COVID-19 with an approved vaccine as shown by various literature. To come up with an effective vaccination program, authorities must understand the willingness of the public to receive vaccines and the reason behind the hesitancy, if there is. 
Previous studies have shown that people will have high vaccine acceptability if it is recommended by their healthcare providers and professionals [30,31]. Several health beliefs have been correlated in past studies with vaccine acceptability, such as the perceived vaccine effectiveness and potential vaccine harms. This, according to Reiter, Pennel, \& Katz (2020), are a central construct of multiple health behavior theories such as the Protection Motivation Theory [31,32]. Meanwhile, a meta-analysis conducted by Xiao \& Wong (2020) on vaccine hesitancy and perceived behavioral control demonstrated the behavioral health model like the Theory of Planned Behavior in explaining vaccine hesitancy [17]. Several studies have urged to enhance tailored interventions and policies to target such beliefs related to vaccine hesitancy in improving knowledge and attitude towards vaccines and increasing vaccination uptake [17,23,33-35]

Few studies have explored the prevalence of COVID-19 vaccine acceptance and its determinants in the Philippines, particularly in the cities of Caloocan, Malabon, and Navotas. These three cities recorded the lowest daily attack rate of COVID-19 among the 17 local government units in the National Capital Region (NCR) according to OCTA Research [36]. Although several surveys on COVID-19 vaccination in these areas have been conducted, these were informal and no sufficient information on the determinants of vaccine acceptance or hesitancy was indicated. In Navotas City, an informal online survey by the local government showed that the majority of their residents are willing to get vaccinated as long as their preferred vaccine is used and that $84.2 \%$ of respondents prefer the Pfizer vaccine [37-39]. Another survey conducted by the Malabon City government showed that only $484(35.7 \%)$ out of 1,356 respondents are willing to be vaccinated [40]. Meanwhile, almost all of the respondents in Caloocan, or 95\% of more than 13,000 respondents, were willing to get vaccinated against 2019, according to an internal survey by the local government [41]. The purpose of this study is to describe the current vaccine acceptance, the reasons or factors behind their willingness or unwillingness to be vaccinated, and the differences between vaccine acceptances of the respondents according to specific demographic variables. Since vaccine acceptancy and hesitancy vary according to geography and socio-demographic characteristics we aim to understand the public willingness to get a COVID-19 vaccine in the future in the cities of Caloocan, Malabon, and Navotas.

\section{Materials and Methods}

This quantitative cross-sectional study employed an anonymous online survey using a questionnaire constructed through Google Forms. Respondents' inclusion criteria were 18 years old residents of the cities of Caloocan, Malabon, and Navotas. Due to the pandemic and considering the existing situation, the researchers adopted a convenience sampling technique, allowing easier access among target respondents, without sacrificing social distancing measures. Data collection was performed by distributing Google Forms via social networks such as Facebook and Messenger.

Data were collected from 19th January to 4th February, equivalent to 14 days, ahead of the target start of the government vaccination program, which was tentatively set by the 3rd and 4th week of February [12]. Only those who accepted the invitation to complete the survey and met the criteria cited above were included in the study. One hundred fifty-two individuals took part in the survey. However, only 137 met the sampling criteria and were included in the results of the study.

The researchers adapted several questions from various studies and surveys on vaccine hesitancy and acceptance [15,42]. The questions were divided into four main themes, namely: 1) demographic profile of the survey respondents, including sex, city of residence, monthly household income, and educational attainment; 2) respondents' willingness to accept COVID-19 vaccine; 3) respondents' reason for willingness or unwillingness to accept COVID-19; and 4) COVID-19 vaccine brand awareness and preference of the respondents. The first question on vaccine acceptability focused on potential availability, "Are you willing or unwilling to get vaccinated if a COVID-19 vaccine 
becomes available?", while another question included safety, effectiveness, and cost in addition to availability as parameters, "Are you willing or unwilling to get vaccinated if a COVID-19 vaccine is proven safe and effective, and become available and free?" Two questions focused on the reasons for the respondents' willingness or unwillingness to be vaccinated. Two questions focused on the awareness of the respondents and their preferred brands COVID-19 vaccines. And the last questions focused on the primary factors that will influence the respondents' decision to be vaccinated. The questionnaire's content and clarity were assessed and validated by selected academicians. The draft questionnaire was pilot tested and the final questionnaire was developed. The survey was offered in the Filipino language and was self-administered online.

The first part of the online survey contains a completed informed consent form. The respondents were duly informed that they could refuse to answer any question, withdraw from the survey at any point in time without any harm and that all data would remain confidential. The online survey adhered to the provisions of the Philippine Data Privacy Act. Respondents who willingly gave consent to participate in the survey were asked to click the submit button and were then directed to complete the questionnaire.

Frequencies and percentages were first calculated to describe the respondents' respondents' willingness or unwillingness to be vaccinated, reasons for such attitude, and individuals or organizations that can influence their decision. The collected data were analyzed using the IBM-SPSS v25. The descriptive analysis focused on frequencies and percentages. Independent-Samples Mann-Whitney U Test was used to compare differences between the respondents' gender and their willingness to get vaccinated if available, and willingness to get vaccinated if proven safe and effective, and is available and free. Meanwhile, the Independent-Samples Kruskal-Wallis test was used to test the significant difference between the respondents' willingness to get a vaccine and their city of residence highest educational attainment, and monthly family income. These non-parametric tests were applied since the samples were derived using non-probability sampling techniques. The statistical significance level was set at $\mathrm{p}<0.05$.

\section{Results}

\subsection{Demographic Characteristics}

In the study, 137 respondents completed the online questionnaire, including 46 $(34 \%)$ men and 91 (66\%) females. Almost half of the respondents are college graduates $(47 \%)$, while $23 \%$ reached college. Almost all of the participants are Roman Catholic $(99 \%)$. In terms of residence, $37 \%$ are from Caloocan, $34 \%$ are from Navotas, and $29 \%$ are from Malabon. The majority of the respondents have a family monthly income of Php15, 000 below (25.5\%) (Table 1$)$.

Table 1. Demographic Profile of the Respondents

\begin{tabular}{|c|c|c|c|}
\hline \multicolumn{2}{|c|}{ Demographic Characteristics } & $\mathrm{f}$ & $\%$ \\
\hline \multirow{2}{*}{ Gender } & Female & 91 & 66 \\
\hline & Male & 46 & 34 \\
\hline \multirow{3}{*}{ City of Residence } & Caloocan & & 37 \\
\hline & Malabon & & 29 \\
\hline & Navotas & & 34 \\
\hline \multirow{7}{*}{$\begin{array}{c}\text { Educational Attain- } \\
\text { ment }\end{array}$} & Elementary Level & 1 & 0.7 \\
\hline & High School Level & 6 & 4 \\
\hline & High School Graduate & 13 & 10 \\
\hline & College Level & 32 & 23 \\
\hline & College Graduate & 64 & 47 \\
\hline & Post-Graduate Level & 7 & 5 \\
\hline & Post Graduate & 8 & 6 \\
\hline
\end{tabular}




\begin{tabular}{cccc}
\hline & Vocational & 5 & 4 \\
Prefer not to say & 1 & 0.7 \\
Php5,000 below & 17 & 12 \\
Php5,001 - Php10,000 & 18 & 13 \\
Php10,001 - Php15,000 & 21 & 15 \\
Monthly Income & Php15,001 - Php20,000 & 11 & 8 \\
& Php20,001- Php25,000 & 6 & 4 \\
& Php25,001 and above & 15 & 11 \\
& Prefer not to say & 49 & 36 \\
\hline
\end{tabular}

\subsection{Willingness to get a COVID-19 Vaccine if it becomes Available}

Willingness to get a COVID-19 vaccine differed by demographic characteristics with male ( $41 \%$ get vaccinated) compared to female, residents of Navotas (38\%) compared to Caloocan and Malabon, college (32\%), and graduate degree holders compared to people with lower educational attainment.

Of the 91 female respondents, 39 (43\%) will somehow get vaccinated, while almost half of the male respondents will get the vaccine (41\%). In terms of residence, the majority of the respondents from Caloocan and Malabon will somehow get a vaccine $(36 \%$ and $50 \%$ respectively), while more respondents from Navotas will get a vaccine (38\%). The majority of respondents who reached college level or are college graduates will somehow get a vaccine $(45 \%)$.

Using Independent-Samples Mann-Whitney U Test, the difference between the respondents' willingness to get a vaccine if available and their gender was compared. Results of the test showed that there is no statistically significant difference between the two variables (Table 2).

Meanwhile, the Independent-Samples Kruskal-Wallis test results showed that the differences between the median of the respondents' other demographic characteristics and their willingness to get a vaccine if available are not statistically significant (Table 2).

Table 2. Respondents' Willingness to Get a Vaccine if Available

\begin{tabular}{|c|c|c|c|c|c|c|}
\hline & & $\begin{array}{c}\text { Get } \\
\text { vaccinated } \\
(\mathrm{n}=44) \\
f(\%)\end{array}$ & $\begin{array}{c}\text { Somehow } \\
\text { get } \\
\text { vaccinated } \\
(\mathrm{n}=53) \\
f(\%)\end{array}$ & $\begin{array}{c}\text { Somehow } \\
\text { would not get } \\
\text { vaccinated } \\
(\mathrm{n}=25) \\
f(\%)\end{array}$ & $\begin{array}{c}\text { Definitely } \\
\text { would not } \\
\text { get } \\
\text { vaccinated } \\
(\mathrm{n}=13) \\
f(\%)\end{array}$ & $\mathrm{p}$-value \\
\hline \multirow{2}{*}{ Gender } & Male & $19(41)$ & $14(30)$ & $9(20)$ & $3(7)$ & \multirow{2}{*}{0.198} \\
\hline & Female & $25(28)$ & $39(43)$ & $16(18)$ & $10(11)$ & \\
\hline \multirow{3}{*}{$\begin{array}{l}\text { City of } \\
\text { Residence }\end{array}$} & Caloocan & $16(32)$ & $18(36)$ & $11(22)$ & $5(10)$ & \multirow{3}{*}{0.631} \\
\hline & Malabon & $10(25)$ & $20(50)$ & $6(15)$ & $4(10)$ & \\
\hline & Navotas & $18(38)$ & $15(32)$ & $8(17)$ & $4(9)$ & \\
\hline \multirow{4}{*}{$\begin{array}{l}\text { Educational } \\
\text { Attainment }\end{array}$} & High School Level & $2(33)$ & $2(33)$ & - & $2(33)$ & \multirow{4}{*}{0.897} \\
\hline & High School Graduate & $5(36)$ & $3(23)$ & $2(15)$ & $3(23)$ & \\
\hline & College Level & $9(28)$ & $10(31)$ & $11(34)$ & $2(6)$ & \\
\hline & College Graduate & $21(32)$ & $29(45)$ & $9(14)$ & $4(6)$ & \\
\hline
\end{tabular}




\begin{tabular}{|c|c|c|c|c|c|c|}
\hline & Post-Graduate Level & $4(57)$ & $1(14)$ & $1(14)$ & \multicolumn{2}{|l|}{$1(14)$} \\
\hline & Post-Graduate & $2(25)$ & $5(63)$ & - & \multicolumn{2}{|l|}{$1(13)$} \\
\hline & Vocational & $1(20)$ & $2(40)$ & $2(40)$ & \multicolumn{2}{|l|}{-} \\
\hline & Php5,000 below & $6(35)$ & $4(24)$ & $5(29)$ & \multicolumn{2}{|l|}{$2(12)$} \\
\hline & Php5,001 - Php10,000 & $9(50)$ & $4(22)$ & $2(11)$ & \multicolumn{2}{|l|}{$2(11)$} \\
\hline Monthly & Php10,001 - Php15,000 & $6(29)$ & $10(48)$ & $3(14)$ & \multicolumn{2}{|l|}{$1(5)$} \\
\hline Family & Php15,001 - Php20,000 & $3(27)$ & $6(55)$ & $1(9)$ & $1(9)$ & 0.668 \\
\hline Income & Php20,001 - Php25,000 & $2(33)$ & $3(50)$ & $1(17)$ & \multicolumn{2}{|l|}{-} \\
\hline & Php25,001 - Php30,000 & $6(40)$ & $6(40)$ & $1(7)$ & \multicolumn{2}{|l|}{$2(13)$} \\
\hline & Prefer not to say & $11(26)$ & $17(41)$ & $11(26)$ & \multicolumn{2}{|l|}{$3(7)$} \\
\hline
\end{tabular}

\subsection{Demographic Characteristics}

Among those respondents who will get a vaccine, $62 \%$ said they will do so to "ensure they are safe from COVID-19", $48 \%$ said they "believe that the vaccine is safe", and $35 \%$ answered, "I know that the vaccine is safe." Another $13 \%$ will only get a vaccine if the COVID-19 situation becomes worse. Meanwhile, $64 \%$ of the respondents who are likely not to get a vaccine said that "they are not sure if the vaccine is safe", while $43 \%$ answered, "I am not sure if the vaccine is effective". Around 23\% attributed their choice of not getting a vaccine to the changing decisions of the government about the vaccine, while $21 \%$ said that they "do not trust the vaccine against COVID-19" (Table 3).

Table 3. Respondents' Reason for Willingness or Unwillingness to Get a Vaccine if Available

\begin{tabular}{lcc}
\hline Reasons for willingness to get a COVID-19 vaccine $\mathbf{( n = 9 7 )}$ & $\mathrm{f}$ & $\%$ \\
\hline I believe that the vaccine is effective & 33 & 35 \\
I believe that the vaccine is safe & 45 & 48 \\
I will take a vaccine if COVID-19 gets worse & 12 & 13 \\
I will take a vaccine to ensure my safety against COVID-19 & 58 & 62 \\
I will take a vaccine to follow government instructions/policies & 9 & 10 \\
I will take a vaccine because it is cheap & 8 & 9 \\
No answer & 2 & 2 \\
\hline Reasons for unwillingness to get a COVID-19 vaccine (n=38) & $\mathrm{f}$ & $\%$ \\
\hline I am not sure if the vaccine is safe & 28 & 64 \\
I am not sure if the vaccine is effective & 19 & 43 \\
I am not sure about the possible side effects of getting a vaccine & 18 & 41 \\
The government has been changing decisions concerning the & 10 & 23 \\
vaccine & 10 & 23 \\
There might be some allergic reactions if I take a vaccine & 9 & 20 \\
I do not trust the vaccine against COVID-19 & 4 & 9 \\
I believe I am safe from COVID-19 even without getting a vaccine & 4 & 9 \\
I am too old to get a vaccine & 3 & 7 \\
I will not take a vaccine if the COVID-19 does not get worse & 10 & 23 \\
No answer & &
\end{tabular}




\subsection{Willingness to get a COVID-19 Vaccine if Prove Safe and Effective and if Available and Free}

When the respondents were asked if they would get a COVID-19 vaccine if proven safe and effective and is available and free, the number of respondents who would get the vaccine increased to $51 \%$, while $31 \%$ would somehow get the vaccine, for a total of $82 \%$. Only $18 \%$ answered negatively.

As shown in Table 4, half of the female respondents and more than half of them (54\%) male respondents would get the vaccine if prove safe and effective, and if available and free. In terms of residence, $54 \%$ of Caloocan residents, $57 \%$ of Navotas residents, and $40 \%$ of Malabon residents would get the vaccine. Of the 64 college graduates, $50 \%$ will get a vaccine, while $44 \%$ of those who reached the college level will get a vaccine. In terms of monthly family income, the majority of the respondents whose families are earning Php10,001-Php15,000 (52\%) will get a vaccine. However, more respondents have lower monthly family income who will likely not get vaccinated.

However, results of the Mann-Whitney U test for gender and the Kruskal-Wallis test for the city of residence, educational attainment, and monthly family incomed showed that there are no statistically significant differences in the respondents' demographic characteristics and their willingness to get a vaccine if proven safe and effective and if available and free (Table 4).

Table 4. Respondents' Willingness to Get a Vaccine if proven Safe and Effective, and if Available and Free

\begin{tabular}{|c|c|c|c|c|c|c|}
\hline & & $\begin{array}{c}\text { Get } \\
\text { vaccinated } \\
(\mathrm{n}=70) \\
f(\%)\end{array}$ & $\begin{array}{c}\text { Somehow } \\
\text { get } \\
\text { vaccinated } \\
(n=59) \\
f(\%)\end{array}$ & $\begin{array}{c}\text { Somehow } \\
\text { would not get } \\
\text { vaccinated } \\
(\mathrm{n}=14) \\
f(\%)\end{array}$ & $\begin{array}{c}\text { Definitely } \\
\text { would not } \\
\text { get } \\
\text { vaccinated } \\
(\mathrm{n}=10) \\
f(\%)\end{array}$ & p-value \\
\hline \multirow{2}{*}{ Gender } & Male & $25(57)$ & $12(27)$ & $5(11)$ & $2(5)$ & \multirow{2}{*}{0.413} \\
\hline & Female & $45(50)$ & $29(32)$ & $9(10)$ & $8(9)$ & \\
\hline \multirow{3}{*}{$\begin{array}{l}\text { City of } \\
\text { Residence }\end{array}$} & Caloocan & $27(54)$ & $14(28)$ & $6(12)$ & $3(6)$ & \multirow{3}{*}{0.386} \\
\hline & Malabon & $16(40)$ & $17(43)$ & $3(8)$ & $4(10)$ & \\
\hline & Navotas & $27(57)$ & $11(23)$ & $6(13)$ & $3(6)$ & \\
\hline \multirow{7}{*}{$\begin{array}{l}\text { Educational } \\
\text { Attainment }\end{array}$} & High School Level & $2(33)$ & $2(33)$ & - & $2(33)$ & \multirow{7}{*}{0.352} \\
\hline & High School Graduate & $9(69)$ & $1(8)$ & $3(23)$ & - & \\
\hline & College Level & $14(44)$ & $8(25)$ & $8(25)$ & $2(6)$ & \\
\hline & College Graduate & $32(50)$ & $24(38)$ & $3(5)$ & $5(8)$ & \\
\hline & Post-Graduate Level & $4(57)$ & $2(29)$ & - & $1(14)$ & \\
\hline & Post-Graduate & $5(63)$ & $3(38)$ & - & - & \\
\hline & Vocational & $4(80)$ & $1(20)$ & - & - & \\
\hline & Php5,000 below & $8(47)$ & $4(24)$ & $3(18)$ & $2(12)$ & \multirow{5}{*}{0.484} \\
\hline Monthly & Php5,001 - Php10,000 & $13(72)$ & $1(6)$ & $3(17)$ & $1(6)$ & \\
\hline Family & Php10,001 - Php15,000 & $11(52)$ & $8(38)$ & $1(5)$ & $1(5)$ & \\
\hline \multirow[t]{2}{*}{ Income } & Php15,001 - Php20,000 & $5(46)$ & $5(46)$ & - & $1(9)$ & \\
\hline & Php20,001 - Php25,000 & $4(67)$ & $2(33)$ & - & - & \\
\hline
\end{tabular}




\begin{tabular}{lcccc} 
Php25,001 - Php30,000 & $8(53)$ & $4(33)$ & - & $2(13)$ \\
Prefer not to say & $21(43)$ & $17(35)$ & $8(16)$ & $3(6)$ \\
\hline
\end{tabular}

\subsection{COVID-19 Vaccine Awareness and Preference}

When asked which brand of COVID-19 vaccine are they aware of, 59\% chose Cominarty (Pfizer, BioNTech, Fosun Pharma), followed by mRNA-1273 (Moderna, BARDA, NIAID) (40\%), COVID-19 Vaccine AstraZeneca (BARDA, OWS) (37\%), CoronaVac (Sinovac) (33\%), and Sputnik V (Gamaleya Research Institute, Acellena Contract Drug Research, and Development) (21\%). Among these brands, Comirnaty was the preferred brand of vaccine by $32 \%$ of respondents who would get a COVID-19 vaccine. Around $15 \%$ of them will choose COVID-19 Vaccine AstraZeneca, 10\% will choose mRNA-1273 (Moderna, BARDA, NIAID), while 9\% will choose CoronaVac (Sinovac). Around $12 \%$ of them still do not know which brand of COVID-19 vaccine they prefer (Table 5).

Table 5. Respondents' Awareness of and Preference on COVID-19 Vaccines

\begin{tabular}{|c|c|c|c|c|}
\hline & \multicolumn{2}{|c|}{$\begin{array}{c}\text { Awareness of } \\
\text { Vaccine Brand } \\
\text { (multiple responses) }\end{array}$} & \multicolumn{2}{|c|}{$\begin{array}{c}\text { Preferred } \\
\text { Vaccine Brand } \\
\text { (single response) }\end{array}$} \\
\hline & $\mathrm{f}$ & $\%$ & $\mathrm{f}$ & $\%$ \\
\hline Comirnaty (Pfizer, BioNTech, Fosun Pharma) & 81 & 59 & 44 & 32 \\
\hline mRNA-1273 (Moderna, BARDA, NIAID) & 55 & 40 & 13 & 9 \\
\hline $\begin{array}{l}\text { COVID-19 Vaccine AstraZeneca (BARDA, } \\
\text { OWS) }\end{array}$ & 51 & 37 & 21 & 15 \\
\hline CoronaVac (Sinovac) & 45 & 33 & 12 & 9 \\
\hline $\begin{array}{l}\text { Sputnik V (Gamaleya Research Institute, } \\
\text { Acellena Contract Drug Research, and } \\
\text { Development) }\end{array}$ & 29 & 21 & 1 & $<1$ \\
\hline JNJ-78436735 (Johnson \& Johnson) & 11 & 8 & - & - \\
\hline NVX-CoV2373 (Novavax) & 8 & 6 & 1 & $<1$ \\
\hline Covaxin (Bharat Biotech, ICMR) & 7 & 5 & 1 & $<1$ \\
\hline $\begin{array}{l}\text { BBIBP-CorV (Beijing Institute of Biological } \\
\text { Products; China National Pharmaceutical } \\
\text { Group (Sinopharm)) }\end{array}$ & 6 & 4 & - & - \\
\hline EpiVacCorona (Federal Budgetary Research & & & & \\
\hline $\begin{array}{l}\text { Institution State Research Center of Virology } \\
\text { and Biotechnology) }\end{array}$ & 3 & 2 & - & - \\
\hline Convidicea (CanSino Biologics) & 2 & 1 & - & - \\
\hline I don't know & 10 & 7 & 16 & 12 \\
\hline None & - & - & 2 & 1 \\
\hline No answer & 1 & $<1$ & 1 & $<1$ \\
\hline
\end{tabular}


To further understand the respondents' attitudes to the COVID-19 vaccine, they were also asked to identify who or what will primarily encourage them to get a COVID-19 vaccine via an open-ended question. Among the 82 respondents who will are willing to get a COVID-19 vaccine, the most mentioned choices were "doctor/medical experts" (15\%), followed by "church" (13\%), "family" (12\%), and only self (11\%). Other respondents also mentioned the "government (including local government, Department of Health, and President Rodrigo Duterte" (11\%), "science/scientific results" (7\%), and the "effectiveness of the vaccine" (6\%) (Table 6).

Table 6. Individuals or Groups will Encourage Respondents to Get a COVID-19 Vaccine

\begin{tabular}{lcc}
\hline & $\mathrm{f}$ & $\%$ \\
\hline Family/Sibling/Children/Parents & 18 & 22 \\
Doctor/Medical Experts/WHO & 14 & 17 \\
Church & 13 & 16 \\
Self & 9 & 11 \\
Government (including local government, & 9 & 11 \\
Department of Health, President Rodrigo Duterte) & & \\
Science/Scientific Results & 6 & 7 \\
Effectiveness of the vaccine & 5 & 6 \\
Not sure & 5 & 6 \\
Others & 4 & 5 \\
\hline
\end{tabular}

\section{Discussion}

Vaccine hesitancy is an old phenomenon and has been a longstanding problem for many countries that have become a serious threat to the global health system [43]. This phenomenon has resulted in the resurgence of infectious diseases in many countries, including the Philippines. And with the ongoing effort to control the spread of COVID-19, the global efforts to develop, produce and distribute vaccines can be hampered by hesitancy among the public. In the Philippines, the government has been doing a lot of efforts to promote COVID-19 vaccinations among the general public, assuring the vaccines' safety and efficacy, especially those granted with Emergency Use Authorization (EUA) by the Food and Drug Administration (FDA) [2]. Despite these efforts, vaccine hesitancy has resulted in lower vaccination rates in recent years [44]. Amidst the ongoing effort to ensure higher COVID-19 vaccination rates once the inoculation program starts, several poll surveys have revealed a high rate of hesitancy among Filipinos. These might negatively affect the necessary target to stop the pandemic through herd immunity by vaccination, which can only be achieved if a large proportion of the total population is vaccinated [45]. Therefore, it is critical for those in authority to come up with appropriate strategies to help mitigate the impact of vaccination hesitancy on the government's inoculation plan against COVID-19. And this can only be done by understanding the reasons behind the willingness or unwillingness of the public to be vaccinated. This is most appropriate for local government authorities of the cities of Caloocan, Malabon, and Navotas, which have recorded the lowest attack rate among the cities in the NCR in 2020, and whose informal surveys showed different results in terms of their residents' willingness to get vaccinated, which also did not reveal the reasons behind such attitudes. 
This study, although very limited in terms of the sample, still provides important and timely insights into how selected residents from the three cities view COVID-19 vaccination, and how willing or unwilling are the respondents to be vaccinated against the disease.

The online COVID-19 survey found that seven of ten respondents will take a COVID-19 vaccine if it is available. This increased to eight of ten respondents when they were asked if they will get a vaccine if it is proven safe and effective and is available and free. Also, willingness to get a vaccine is relatively high across the three cities of Caloocan, Malabon, and Navotas, and the rate of unwillingness does not vary in terms of residence. The results prove that the assurance that vaccines are safe and effective, in addition to their cost, are important factors that will persuade more people to get vaccinated [23]. However, it is still important to take note that the number of very unwilling respondents is still high, and if more people are unwilling to get a vaccine, this might delay the government's campaign to control the pandemic.

Several factors were found to contribute to the unwillingness of some of these respondents to get a COVID-19 vaccine. Vaccine safety and effectiveness was the most important factor that affects the respondents' intent to receive a COVID-19 vaccine. A majority of the respondents who are willing to get a vaccine believe the vaccines will make them safe from COVID-19, and that the vaccines are safe. Likewise, the majority of those who are unwilling don't think the vaccines are safe. Other safety-related concerns include the potential side effects and allergic reactions that might happen to those who will be vaccinated. The findings reinforce the results of many international studies that ensuring safety from COVID-19, vaccine safety, effectiveness, and side effects are primary concerns among the public [46,47]. Therefore, any effective measures to promote COVID-19 vaccination should focus on promoting the benefits of vaccination, as well as the safety and effectiveness of the vaccines [4]. These findings are relevant since they emphasize some of the factors or determinants of willingness to accept COVID-19 vaccines, especially that the distribution of vaccines and inoculation programs have started despite a shorter period of development. National government agencies and the local government units, which in the study were only limited to the cities of Caloocan, Malabon, and Navotas, should also ensure a transparent process to increase public trust in vaccines' safety and effectiveness. If the programs to promote the vaccination are not properly handled, this might affect the public's confidence in vaccines.

COVID-19 vaccine communication strategies should also consider other members of the society who have an important role to play to influence the public's willingness to be vaccinated. These include immediate members of the family, medical experts, church ministries and organizations, and businesses and employers. Promotion of pro-vaccination principles such as vaccine safety and efficacy must target these sectors, and the government must use them as positive influencers.

Another important finding is that Comirnaty (Pfizer) is the only brand that more than half of the respondents are aware of (59\%), followed by mRNA-1273 (Moderna) $(40 \%)$, AstraZeneca (37\%), and Sinovac (33\%). Likewise, Comirnaty was also the most preferred type of vaccine (32\%) followed by the AstraZeneca brand (15\%). However, during the time that this paper was written, the government has only secured the delivery of two COVID-19 vaccines - Sinovac and AstraZeneca. Local governments must therefore work harder to increase awareness and acceptability of these vaccines among the public.

The major limitation of this study is the sample size and the technique they were selected, which affects the generalizability of the results. Sampling was done using convenience non-probability sampling, which resulted in a low number of respondents, given the existing situation in these three places. Moreover, because the study utilized an online self-administered survey method, there might be potential bias in reporting the results of the study. There is also the possibility of selection bias, which might result in the underrepresentation of certain sectors. This could also be related to the lack of a good internet connection. Thus, the findings may not represent the true picture of the wider 
population of residents in Caloocan, Malabon, and Navotas. Future researchers must conduct a more systematic, probability-based sampling method to come up with more representative and generalizable results. Second, the study is cross-sectional, which depicts a picture of the respondents' responses at the point of the study. And since the researchers asked the respondents to report their intention to receive the COVID-19 vaccine if it is available in the future, there is a high number of respondents who answered "not sure" or "I don't know". The real willingness of the respondents might differ if the vaccines are available. Researchers may also want to utilize other instruments on vaccine hesitancy and include questions about vaccination promotion strategies, time spent in vaccination, vaccine efficacy, barriers in COVID-19 vaccination, and location of vaccine development and production. Also, other important demographic characteristics such as age and employment status can be included for further analysis. Age brackets were excluded from the results due to a high number of non-responses.

\section{Conclusions}

Through this study, we found that majority of the respondents are willing to get vaccinated, regardless of their residence, sex, educational attainment, and monthly family income. Perceived risk on the safety and effectiveness of the COVID-19 vaccines were found to be significant factors that affect the respondents' willingness to get a COVID-19 vaccine. Likewise, a large number of respondents have preferred brands in mind, which might affect the vaccination program of the government. Elaborate health education and vaccine promotion should be conducted to improve vaccine acceptance during the COVID-19 inoculation programs, especially that the most preferred brands are not all available. The government must also target the head of the families, doctors and medical practitioners, and Church personalities and make them primary influences to encourage more people to be vaccinated.

Author Contributions: Conceptualization, Angelito Bautista Jr., Doris Bleza and Dianne Balibrea; Formal analysis, Angelito Bautista Jr. and Cynthia Equiza; Methodology, Angelito Bautista Jr. and Cynthia Equiza; Software, Angelito Bautista Jr.; Supervision, Angelito Bautista Jr.; Validation, Angelito Bautista Jr., Doris Bleza and Dianne Balibrea; Writing - original draft, Angelito Bautista Jr. and Dianne Balibrea; Writing - review \& editing, Doris Bleza.

Funding: This research received no external funding.

Institutional Review Board Statement: Not applicable.

Informed Consent Statement: Informed consent was obtained from all respondents who participated in the survey.

Data Availability Statement: Readers can access the data supporting the conclusions of the study upon email request. The names and personal data of the respondents cannot be released, due to ethical aspects.

Acknowledgments: Special thanks to the Diocese of Kalookan - Public and Political Affairs Ministry (DoK-PPAM) for supporting us in the conduct of the study. Coordinators of the DoK-PPAM helped in the distribution of the online survey questionnaires.

Conflicts of Interest: The authors declare no conflict of interest.

\section{References}

1. World Health Organization. Clinical management of severe acute respiratory infection (SARI) when COVID-19 disease is suspected. https://www.who.int/docs/default-source/coronaviruse/clinical-management-of-novel-cov.pdf (accessed on 05 February 2021).

2. John Hopkins University. COVID-19 Map. https://coronavirus.jhu.edu/map.html (accessed on 18 April 2021). 
3. Kabamba Nzaji, M.; Kabamba Ngombe, L.; Ngoie Mwamba, G.; Banza Ndala, D. B.; Mbidi Miema, J.; Luhata Lungoyo, C.; ... Mukamba Musenga, E. Acceptability of Vaccination Against COVID-19 Among Healthcare Workers in the Democratic Republic of the Congo. Pragmatic and Observational Research 2020, 11, 103-109. https://doi.org/10.2147/por.s271096

4. Pogue K. et. al. Influences on attitudes regarding potential COVID-19 vaccination in the United States. Vaccines 2020, 8(4), 582. https://doi.org/10.3390/vaccines8040582

5. World Health Organization. Accelerating a safe and effective COVID-19 vaccine. https://www.who.int/emergencies/diseases/novel-coronavirus-2019/global-research-on-novel-coronavirus-2019-ncov/acce lerating-a-safe-and-effective-covid-19-vaccine (accessed 05 February 2021).

6. Felter, C. A Guide to Global COVID-19 Vaccine Efforts. Council on Foreign Relations. 2021, https://www.cfr.org/backgrounder/guide-global-covid-19-vaccine-efforts (accessed on 12 March 2021).

7. World Health Organization. WHO issues its first emergency use validation for a COVID-19 vaccine and emphasizes the need for equitable global access. https://www.who.int/news/item/31-12-2020-who-issues-its-first-emergency-use-validation-for-a-covid-19-vaccine-and-em phasizes-need-for-equitable-global-access (accessed on 05 February 2021).

8. BBC News. Covid-19 vaccine: First-person receives Pfizer jab in the UK. BBC News. https://www.bbc.com/news/uk-55227325 (accessed on 05 February 2021).

9. BBC News. Covid-19: The first vaccine is given in the US as roll-out begins. BBC News. https://www.bbc.com/news/world-us-canada-55305720 (accessed on 05 February 2021).

10. World Health Organization. Draft landscape and tracker of COVID-19 candidate vaccines. https://www.who.int/publications/m/item/draft-landscape-of-covid-19-candidate-vaccines (accessed on 12 March 2021).

11. Tomacruz, S. TIMELINE: The Philippines' 2021 COVID-19 vaccine plan. Rappler. https://www.rappler.com/newsbreak/iq/timeline-philippines-2021-covid-19-vaccination-plan (accessed on 12 February 2021).

12. Tomacruz, S. Philippines eyes start of COVID-19 vaccine rollout by end-February $2021 . \quad$ Rappler. https://www.rappler.com/nation/philippines-eyes-start-coronavirus-vaccine-rollout-end-february-2021 (accessed on 05 February 2021).

13. Department of Health. $\mathrm{PH}$ to receive $5 \mathrm{~m}$ to $9 \mathrm{~m}$ ASTRAZENECA doses from COVAX by Q2. https://doh.gov.ph/doh-press-release/PH-TO-RECEIVE-5M-TO-9M-ASTRAZENECA-DOSES-FROM-COVAX-BY-Q2 (accessed on 12 February 2021).

14. Morales, N. J. Philippines to receive FIRST COVID-19 vaccines, start inoculations next week. Reuters. https://www.reuters.com/article/us-health-coronavirus-philippines-vaccin-idUSKBN2AP0JR (accessed on $10 \mathrm{March} 2021$ ).

15. Lazarus, J. V.; Ratzan, S.; Palayew, A.; Gostin, L. O.; Larson, H. J.; Rabin, K.; ... El-Mohandes, A. Hesitant or not? A global survey of potential acceptance of a COVID-19 vaccine. Nature Medicine 2020, 27, pages225-228(2021). https://doi.org/10.1038/s41591-020-1124-9

16. Padhi, B. K. \& Al-Mohaithef, M. Determinants of COVID-19 vaccine acceptance in Saudi Arabia: a web-based national survey. Dovepress 2020, 13, Pages 1657-1663 https://doi.org/10.2147/JMDH.S276771

17. Xiao, X.; Wong, R. M. Vaccine hesitancy and perceived behavioral control: A meta-analysis. Vaccine 2020, 38(33), $5131-5138$. https://doi.org/10.1016/j.vaccine.2020.04.076

18. Larson, H.J.; Jarrett, C.; Eckersberger, E.; Smith, D.M.D.; Paterson, P. Understanding vaccine hesitancy around vaccines and vaccination from a global perspective: a systematic review of published literature, 2007-2012. Vaccine 2014, 32(19), 2150-2159. https://doi.org/10.1016/j.vaccine.2014.01.081

19. Gidengil, C. A.; Parker, A. M.; Zikmund-Fisher, B. J. Trends in Risk Perceptions and Vaccination Intentions: A Longitudinal Study of the First Year of the H1N1 Pandemic. American Journal of Public Health 2012, 102(4), 672-679. https://doi.org/10.2105/ajph.2011.300407

20. World Health Organization. Top Ten Threats to Global Health in 2019. https://www.who.int/news-room/spotlight/ten-threats-to-global-health-in-2019 (accessed on 05 February 2021).

21. Palamenghi, L.; Barello, S.; Boccia, S.; Gragna, G. Mistrust in biomedical research and vaccine hesitancy: The forefront challenge in the battle against COVID-19 in Italy. European Journal of Epidemiology 2020, 35, 785-788. https://doi.org/10.1007/s10654-020-00675-8

22. Sun, S.; Lin, D.; Operario, D. Interest in COVID-19 vaccine trials participation among young adults in China: Willingness, reasons for hesitancy, and demographic and psychosocial determinants. medRxiv 2020 (Preprint). https://doi.org/10.1101/2020.07.13.20152678

23. Halpin, C.; Reid, B. Attitudes and beliefs of healthcare workers about influenza vaccination. Nursing Older People 2019, 31(2), 32-39. https://doi.org/10.7748/nop.2019.e1154

24. Setbon, M.; Raude, J. Factors in vaccination intention against the pandemic influenza A/H1N1. The European Journal of Public Health 2010, 20(5), 490-494. https://doi.org/10.1093/eurpub/ckq054

25. Smith, T. C. Vaccine Rejection and Hesitancy: A Review and Call to Action. Open Forum Infectious Diseases 2017, 4(3). https://doi.org/10.1093/ofid/ofx146

26. Dyer, O. Philippines measles outbreak is deadliest yet as vaccine skepticism spurs disease comeback. The BMJ. https://www.bmj.com/content/364/bmj.1739 (accessed on 12 February 2021). 
27. Icamina, P. Philippine disease outbreaks linked to vaccine fear. https://www.scidev.net/asia-pacific/features/philippine-disease-outbreaks-linked-to-vaccine-fear (accessed on 05 February 2021).

28. ABS-CBN News. UNICEF: PH immunization coverage dropping at alarming rate. ABS-CBN News. https://news.abs-cbn.com/news/05/08/19/unicef-ph-immunization-coverage-dropping-at-alarming-rate (accessed on 05 February 2021).

29. 'CNN Philippines. OCTA survey: Only 25\% of Metro Manila respondents willing to get COVID-19 vaccine. CNN. https://cnnphilippines.com/news/2021/1/5/COVID-19-vaccine-survey-Metro-Manila-.html (accessed on 05 February 2021).

30. Paterson, P.; Meurice, F.; Stanberry, L. R.; Glismann, S.; Rosenthal, S. L.; Larson, H. J. Vaccine hesitancy and healthcare providers. Vaccine 2016, 34(52), 6700-6706. https://doi.org/10.1016/j.vaccine.2016.10.042

31. Reiter, P. L.; Pennell, M. L.; Katz, M. L. Acceptability of a COVID-19 vaccine among adults in the United States: How many people would get vaccinated? Vaccine 2020, 38(42), 6500-6507. https://doi.org/10.1016/j.vaccine.2020.08.043

32. Rogers. R.W. Cognitive and physiological processes in fear appeals and attitude change: A revised theory of protection motivation. In: Cacioppo J.T., Petty R.E., editors. Social psychophysiology: A source book, 1983. Guilford Press. https://www.researchgate.net/publication/229068371 Cognitive and physiological processes in fear appeals and attit ude change_A revised theory of protection motivation

33. Habersaat, K.B.; Jackson, C. Understanding vaccine acceptance and demand - and ways to increase them. Bundesgesundheitsblatt Gesundheitsforschung Gesundheitsschutz 2020, 63(1), 32-39. https://doi.org/10.1007/s00103-019-03063-0

34. Larson, H. J.; Clarke, R. M.; Jarrett, C.; Eckersberger, E.; Levine, Z.; Schulz, W. S.; Paterson, P. Measuring trust in vaccination: A systematic review. Human Vaccines $\mathcal{E}$ Immunotherapeutics 2018, 14(7), 1599-1609. https://doi.org/10.1080/21645515.2018.1459252

35. Gargano, L.M.; Herbert, N.L.; Painter, J.E. Development, theoretical framework, and evaluation of a parent and teacher-delivered intervention on adolescent vaccination. Health Promot Pract 2014, 15(4), 556-567. https://doi.org/10.1177/1524839913518222

36. Calalo, A. O. Caloocan, Navotas,\&nbsp;Malabon\&nbsp;have\&nbsp;lowest Covid\&nbsp;attack rate. The Manila Times. https://www.manilatimes.net/2020/10/20/news/national/caloocan-navotas-malabon-have-lowest-covid-attack-rate/782839/ (accessed on 10 February 2021).

37. ABS-CBN News. Valenzuela, Navotas allot funds for COVID-19 vaccines. ABS-CBN News. https://news.abs-cbn.com/news/01/04/21/valenzuela-navotas-allot-funds-for-covid-19-vaccines (accessed on 10 February 2021).

38. Pedrajas, J. Navotas residents prefer Pfizer vaccine - survey. Manila Bulletin. https://mb.com.ph/2021/01/20/navotas-residents-prefer-pfizer-vaccine-survey/ (accessed on 10 February 2021).

39. Pazzibugan, D. Z. More local governments inclined to purchase vaccines. INQUIRER.net. https://newsinfo.inquirer.net/1379467/more-local-governments-inclined-to-purchase-vaccines (accessed on 10 February 2021).

40. ABS-CBN News. Malabon City targets to inoculate more than 100,000 individuals. ABS-CBN News. https://news.abs-cbn.com/news/02/02/21/malabon-city-targets-to-inoculate-more-than-100000-individuals (accessed on 10 February 2021).

41. Ornedo, J. M. Only 35\% of Malabon residents want COVID-19 vaccine, poll shows. GMA News Online. https://www.gmanetwork.com/news/news/metro/774491/only-35-of-malabon-residents-want-covid-19-vaccine-poll-show s/story/ (accessed on 12 February 2021).

42. Social Weather Stations. Social Weather Stations: SWS September 17-20, 2020 National Mobile Phone Survey - Report No. 17: $66 \%$ of adult Filipinos are willing to get the Covid-19 vaccine. https://www.sws.org.ph/swsmain/artcldisppage/?artcsyscode=ART-20201119203953 (accessed on 05 February 2021).

43. Sallam, M. COVID-19 vaccine hesitancy worldwide: a systematic review of vaccine acceptance rates. Vaccines 2021, 9(2), 160. https://doi.org/10.3390/vaccines 9020160

44. Thaker, J.; Menon, V. Aotearoa-New Zealand Public Attitudes to COVID-19 Vaccine. Massey University. Wellington, New Zealand, 2020. https://mro.massey.ac.nz/handle/10179/15567

45. Department of Health. DOH identifies vaccine hesitancy as one of the reasons for measles outbreak. https://doh.gov.ph/node/16721 (accessed on 05 February 2021).

46. Anderson, R. M.; Vegvari, C.; Truscott, J.; Collyer, B. S. Challenges in creating herd immunity to SARS-CoV-2 infection by mass vaccination. The Lancet 2020, 396(10263), 1614-1616. https://doi.org/10.1016/s0140-6736(20)32318-7

47. Wagner, A. L.; Huang, Z.; Ren, J.; Laffoon, M.; Ji, M.; Pinckney, L. C.; ... Zikmund-Fisher, B. J. Vaccine Hesitancy and Concerns About Vaccine Safety and Effectiveness in Shanghai, China. American Journal of Preventive Medicine 2021, 60(1). https://doi.org/10.1016/j.amepre.2020.09.003

48. Dodd, R. H.; Pickles, K.; Nickel, B.; Cvejic, E.; Ayre, J.; Batcup, C.; ... McCaffery, K. J. Concerns and motivations about COVID-19 vaccination. The Lancet Infectious Diseases 2020, 21(2), 161-163. https://doi.org/10.1016/s1473-3099(20)30926-9

49. World Health Organization. Polio outbreak- The Philippines. World Health Organization. https://www.who.int/csr/don/24-september-2019-polio-outbreak-the-philippines/en/\#: :text=On\%2019\%20September\%20 2019\%2C\%20the,also\%20tested\%20positive\%20for\%20VDPV2 (accessed on 05 February 2021). 